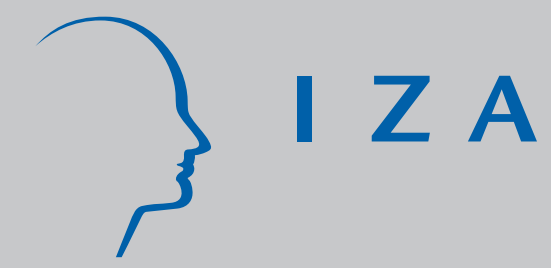

IZA DP No. 367

Parental Background, Primary to Secondary

School Transitions, and Wages

Christian Dustmann

September 2001 


\title{
Parental Background, Primary to Secondary School Transitions, and Wages
}

\author{
Christian Dustmann \\ University College London, CEPR, London \\ and IZA, Bonn
}

\author{
Discussion Paper No. 367 \\ September 2001
}

\author{
IZA \\ P.O. Box 7240 \\ D-53072 Bonn \\ Germany \\ Tel.: +49-228-3894-0 \\ Fax: +49-228-3894-210 \\ Email: iza@iza.org
}

This Discussion Paper is issued within the framework of IZA's research area The Future of Work. Any opinions expressed here are those of the author(s) and not those of the institute. Research disseminated by IZA may include views on policy, but the institute itself takes no institutional policy positions.

The Institute for the Study of Labor (IZA) in Bonn is a local and virtual international research center and a place of communication between science, politics and business. IZA is an independent, nonprofit limited liability company (Gesellschaft mit beschränkter Haftung) supported by the Deutsche Post AG. The center is associated with the University of Bonn and offers a stimulating research environment through its research networks, research support, and visitors and doctoral programs. IZA engages in (i) original and internationally competitive research in all fields of labor economics, (ii) development of policy concepts, and (iii) dissemination of research results and concepts to the interested public. The current research program deals with (1) mobility and flexibility of labor markets, (2) internationalization of labor markets and European integration, (3) the welfare state and labor markets, (4) labor markets in transition, (5) the future of work, (6) project evaluation and (7) general labor economics.

IZA Discussion Papers often represent preliminary work and are circulated to encourage discussion. Citation of such a paper should account for its provisional character. 


\title{
ABSTRACT
}

\section{Parental Background, Primary to Secondary School Transitions, and Wages*}

The degree to which economic status is transmitted from one generation to the next is an important indicator for the inequality of opportunities. One crucial element of intergenerational mobility is the way parents influence the education of their children. Unlike in the UK or in the US, in Germany an important decision about which educational track to follow is made at a relatively early stage: after primary school, at around the age of ten. In this paper, we use micro data to analyse the association between parents' education and professional class and secondary track school choice and subsequent career prospects of the child. Our analysis covers the last 6 decades. We demonstrate that parents' educational background and professional class are strongly related to the secondary track school the child follows, and subsequent educational achievements. We find a slight convergence for individuals from different parental background over the last decades. We also find convergence between males and females. The relationship between parental class and children's education translates into earnings differentials later in life.

JEL Classification: I2, J24, J31

Keywords: Education, parental background, school transitions

\author{
Christian Dustmann \\ Department of Economics \\ University College London \\ Gower Street \\ London WC1E 6BT \\ UK \\ Tel.: +442076795832 \\ Fax: +44 2079162775 \\ Email: c.dustmann@ucl.ac.uk
}

\footnotetext{
* I am grateful to Wendy Carlin and John Micklewright for useful comments on earlier versions of this paper.
} 


\section{Introduction}

Social scientists have long been interested in the degree to which poverty, or wealth is transmitted from one generation to the next. In recent years, economists have taken a strong interest in this matter. One growing strand of research in economics investigates intergenerational mobility of income status, trying to establish the correlation between a parent's position in the income distribution, and that of his or her children. This usually takes the form of regressing some measures of permanent income, or economic status of the child, on a measure of permanent parental income, or economic status. Recent research by Zimmermann (1992) and Solon (1992) for the US establishes estimates of intergenerational mobility that are smaller than previously thought. Dearden, Machin and Reed (1997) estimate coefficients of similar magnitude than the US studies. Comparing the US and UK evidence with results for other European countries (see Bjoerklund and Jaenti 1997, for Sweden, and Wiegand, 1999 for Germany) indicates that intergenerational mobility is slightly larger in Europe than in the US and the UK.

This research does not touch on the mechanisms that explain intergenerational mobility of income status, nor does it provide much explanations for the differences in mobility across countries. If enhancement of the economic mobility across generations is a policy objective, then an understanding of these mechanisms is important, however. In this paper, we take a slightly different approach to this issue. We argue that one of the crucial factors for intergenerational mobility is the way educational institutions allow parents to influence the education of their children. Education is a process that

proceeds in stages, and early educational career decisions have a strong effect on the choices available at later stages. At what age these decisions are taken, and how heavily they affect future opportunities, varies between countries, and may be a key factor in explaining across-country variations in intergenerational mobility. 
Simple economic models on investment in human capital (for instance, Ben Porath, 1967) work on the assumption that education is primarily a matter of individual choice. This may be the case at later stages of the individual's educational career, but early educational decisions are likely to be heavily affected by parental background. A recent literature provides strong empirical evidence for a link between overall educational achievements and parental background (see, for instance, Feinstein and Symons 1999 and Ermisch and Francesconi 2001 for the UK). There are a number of reasons for this association. First, wealthy parents may be able to afford better schools for the child. Second, there is a link between parental background, and the performance in ability tests used as entry condition for schools of different quality in countries like the UK. ${ }^{1}$

A further reason is that education and professional class may shape parents' taste and perception of what is an appropriate educational and professional career for the child. Even in the absence of financial constraints, working class parents may not fully appreciate the value of education, and consider a lower track education, and an early labour market entry the best option for their child. Parental preferences for similar careers of their child to their own are possibly large in societies with strong professional traditions.

The influence of the parents on their child's educational career is likely to be the more significant, the younger the age at which a decision has to be taken. A most important stage in this process is the choice of schools that qualify pupils for university education. In the UK, the choice for continued schooling that qualifies pupils for university or other academic education is taken at the age of 16 . In the US, high school attendance that qualifies for college education is almost compulsory - according

\footnotetext{
${ }^{1}$ Recent research by Robertson and Symons (1996) shows that parental background explains a large part of the variation in ability tests of British school children taken at various ages (age 7, 11, 16).
} 
to the Bureau of Labour Statistics, about 85 percent of a cohort finish high school successfully. Germany has a three-track system of secondary education. In 1990, only 27 percent of school graduates graduated from the highest secondary track schools. It is only the highest track (corresponding to high school in the US, or A-levels in the UK) that allows for direct access to the university system. The decision about which track to follow is usually made at a relatively early stage: after primary school, at about the age of ten.

The fact that this important choice is made at a relatively young age is an often overlooked feature of the German education system. Most research does not address the primary to secondary school transition, but starts with transitions after secondary school education (see Riphan 1999, Merz and Schimmelpfennig 1998; Couch 1994 provides comparisons of transition patterns between the US and Germany). In particular the apprenticeship training scheme and subsequent transitions into the labour market have attracted a lot of interest in other countries (see, for instance, Winkelmann 1996a, 1996b, Steedman 1993 and Buechtemann et al. 1993). The earlier primary-secondary school transition is usually neglected, but, as we argue here, nevertheless important for a full understanding of after secondary school transitions. ${ }^{2}$

There are some distinctive characteristics of the school system in Germany. First, all primary and secondary schools are state schools. Large variations in school quality according to school types, as, for instance, in the UK (private versus state, comprehensive versus grammar etc.), do not exist. Second, schools at all levels (including universities) have offered (since the 1950's) tuition free education. Third, ability tests which provide some indication about the child's potential (and which are common in

\footnotetext{
${ }^{2}$ There is some work by Buechel et al. (2000) that analyses the impact of poverty and income on the educational track teenagers are following. They find a strong association between income and the tendency to attend higher track schools.
} 
the UK and in the US) are not (any more) common in Germany. There are recommendations by the primary school teacher about which secondary track to choose, but these recommendations are not binding. These features of the German education system, and in particular the egalitarian structure and the state provided financing, contribute to the general view that the system provides equal opportunities of educational choice.

In this paper, we show that educational mobility may nevertheless be limited. We argue that one reason is the early choice of the secondary school education track, which is heavily affected by the advice and the influence of the parents. Germany has strong professional traditions. This may lead to intergenerational immobility in educational achievements, and offset the advantages of a tuition free education system. We demonstrate that the secondary school track the child follows is strongly correlated with post-school educational choices, and that parental background, by way of association with secondary track schools, has a most significant association with the economic career of the individual. Our analysis emphasises that it is important to consider educational achievements as a stage process, where the individual may have little influence on decisions if they are taken early in the life cycle. Institutional differences between countries as to when these decisions have to be taken may be important in explaining differences in intergenerational mobility across countries.

We commence by analysing the association of parental education and professional class with the choice of secondary school education of the child over the last six decades. We demonstrate that this association is very strong. There is a tendency of convergence for individuals from different parental background over time. There is also a tendency of convergence between males and females, with a substantial move of females towards higher track education. We then illustrate that secondary school track choice has strong consequences for after-secondary education, and for the earnings position of 
the individual. We estimate wage regressions, and simulate educational achievements and subsequent earnings for individuals with different parental background. Our analysis distinguishes between cohort and age effects, and isolates the effect of parental background on wages. We illustrate the difference in wage positions of individuals of different parental background, and how it changes due to a convergence in educational achievement.

We base our analysis on micro data from the German Socio-Economic Panel. Our study covers the last six decades, the years of most dramatic changes in demand for education in Germany. The paper is organised as follows: In section 2 we provide a brief summary of the German educational system and present some descriptive statistics. Section 3 discusses the data. Section 4 presents the results of the empirical analysis, and section 5 concludes.

\section{The German education system}

In Germany ${ }^{3}$ education is in the competence of the states, not of the federal government. The states coordinate their education policies, and there are regular meetings of the State Secretaries of Education. The main features of the educational system are nearly identical across states, as are teachers' employment conditions and salaries. In figure 1, we illustrate the basic structure of the system.

Education starts with the voluntary pre-school kindergarten. Compulsory school attendance begins at the age of six, and ends at the age of eighteen. Primary school

\footnotetext{
${ }^{3}$ The discussion (as well as the empirical analysis) refers to West Germany only. The education system in former East Germany is similar, with slight differences in the length of the various tracks (for instance, grammar school education takes 8, rather than 9 years).
} 
Figure 1: Basic structure of the German educational system

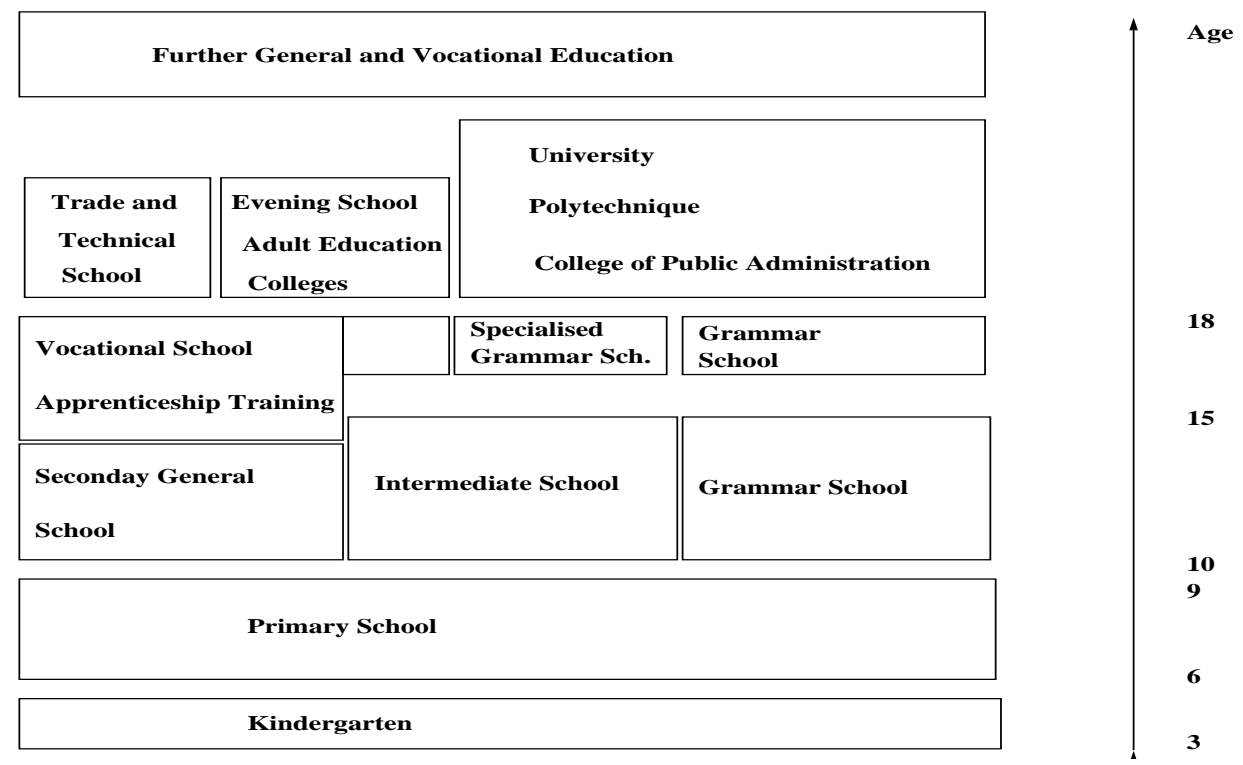

covers the first four years, and provides basic education in reading, writing, and arithmetic. In addition, children are taught preparatory classes in natural sciences, social studies and history. After completing primary school, children continue their education in secondary schools. The three traditional secondary school types are secondary general school (Hauptschule), intermediate school (Realschule), and grammar school (Gymnasium). The secondary general school provides general education as a basis for practical vocational training in years 5 to 9 . During the seventies, most states introduced a voluntary tenth year. In some states the tenth year is now mandatory.

Intermediate school is the second type of the established secondary schools. It covers years 5 to 10 and provides traditionally the basis for further training in whitecollar occupations. The final certificate also qualifies pupils for enrolment at schools for further education and specialised grammar schools.

Grammar school covers years 5 to 13 and serves as a basis for academic education at universities and other institutions of higher education. Upon finishing successfully, 
pupils are awarded a certificate called the Abitur, which allows them to study at academic institutions.

The transition procedure from primary school, where all pupils are taught together, to secondary school underwent a number of changes since 1945. Up to the middle of the fifties, pupils had to pass formal tests if they wanted to enrol in higher secondary schools. One of the main objectives of the reforms during the fifties was to develop a better transition procedure to higher secondary schools. Formal tests were considered as an inappropriate device to measure the abilities of pupils. The states' ministers of education decided in 1960 to base the transition procedure on recommendations of primary school teachers, the parents' preferences, and, if necessary, a "trial-time" in the higher secondary school. Some states continued to use formal tests, but only as an additional device. Besides changing admission procedures, the tuition fees for higher secondary schools were abandoned. Most states dropped tuition fees in the second half of the fifties. After the initial secondary track choice, switching tracks is in principle possible, but rare. Pischke (1999) reports that in 1966, about 7 percent of pupils who decided first for general or intermediate secondary school switched to grammar school - most of them within 3 years of the initial decision.

The demand for secondary school education changed considerably over time. Figure 2 is based on numbers from the 1987 census (the last census in Germany), and displays the evolution in the distribution of secondary school degrees over time. Two features are most striking: first, the decline in the percentage of general school degrees, which is matched by an increase in the shares of intermediate and grammar school degrees. Secondly, the increase in the share of females in intermediate and grammar schools. Until birth cohort 1952 educational attainments for males are continuously higher than for females. This is most obvious if comparing the percentages of grammar school 
Figure 2: Secondary School Degrees, Various Cohorts, Germany

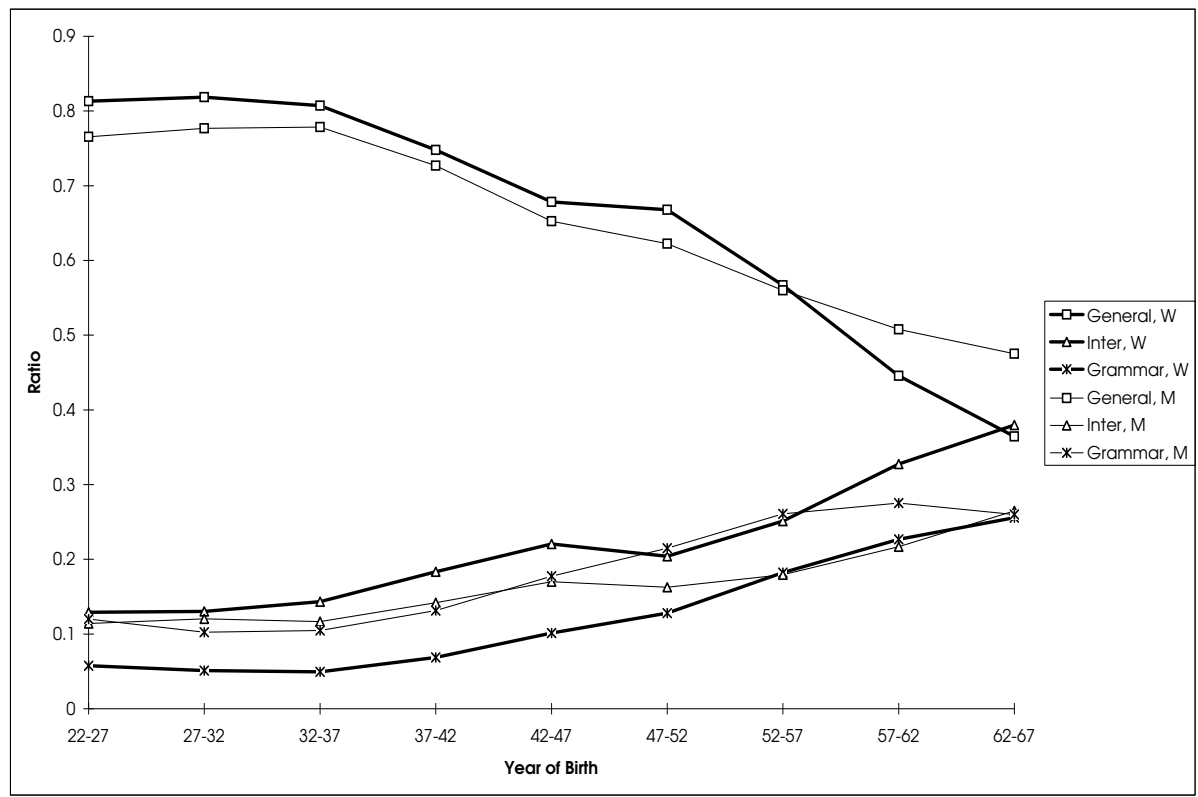


certificates between females and males. After 1952, the proportion of females who graduated from intermediate schools increased more than the proportion of males. For the last birth groups, figure 2 displays nearly the same percentage for female grammar school graduates as for males. For the younger cohorts, the percentage for male general school graduates is considerably higher than for females.

After finishing general or intermediate school, individuals have to enter further education, since compulsory school attendance does not end before the age of eighteen. The most popular choice is to enter the apprenticeship system, which combines parttime attendance at vocational schools with on-the-job training in a company. Between 65 to 70 percent of the German labour force go through this system of combined applied and academic training. Unlike countries like the US and the UK, most white-collar professional degrees are obtained within the apprenticeship system, and not at colleges or universities. Education ends with an examination. Those who pass it successfully are awarded a degree, and considered as skilled workers. They are entitled to further vocational education at trade and technical schools (see figure 1). An alternative to apprenticeship schemes are vocational schools, which are often similar to apprenticeship schemes, and educate individuals who aim, for instance, for a career in the civil service.

The traditional institution of higher education in Germany is the university. It combines teaching and research in a broad range of subjects. Higher education is also provided by colleges of music, arts, theology and education. More practically oriented scientific education is provided by the polytechnics and colleges of public administration. 


\section{The Data}

The data used for this analysis stem from the German Socio-Economic Panel (GSOEP). The GSOEP is a household based panel data set, similar in structure to the British Household Panel Survey (BHPS). The first wave of the panel was collected in 1984 and contains information on 6000 households. Of those, 1500 are a boost sample, consisting of households with a household head of foreign nationality. We restrict our analysis to the 4500 households of the main sample. The third wave of the survey contains detailed information about educational characteristics and job characteristics of each respondent's parents. We construct the educational characteristics of respondents from preceding waves. Because some grammar school pupils may not finish secondary education before the age of 20, we exclude all individuals younger than 21 years from our analysis. Furthermore, to avoid selection due to mortality, we exclude individuals older than 66 years of age.

Information about secondary school degrees refers to the highest degree awarded. As explained above, transfers between types of secondary schools are possible, but not frequent, and take place within 2-3 years of the initial choice being made. Our data does not allow us to not identify individuals who have changed schools. We allocate individuals to one of three groups: individuals who graduated from general school, intermediate school, or grammar school, respectively. Our final working sample contains 3147 females and 2970 males. Table (1) describes the variables used in the analysis and reports sample means.

On average, 64 percent of females have a general secondary school degree; this number is slightly lower for males (60 percent). While 22 percent of males hold a grammar school degree, this number is considerably lower for females (13 percent). Females do however attend intermediate schools more frequently. 
Table 1: Description and Means of Variables

\begin{tabular}{ll|l}
\hline \hline Males & \multicolumn{1}{l}{ Females } & \multicolumn{1}{l}{ Variable } \\
\hline 40.89 & 41.64 & Age of Individual \\
60.41 & 64.12 & General School \\
18.14 & 23.31 & Intermediate School \\
21.92 & 12.98 & Grammar School \\
& & \\
81.68 & 83.61 & Father: General School \\
10.34 & 8.19 & Father: Intermediate School \\
7.96 & 8.19 & Father: Grammar School \\
40.96 & 42.24 & Father: Blue Collar Apprenticeship \\
10.84 & 9.83 & Father: Vocational School after Secondary School \\
9.87 & 10.00 & Father: White Collar Apprenticeship \\
6.09 & 6.16 & Father: University or Polytechnics \\
40.17 & 40.25 & Father: Blue Collar Worker \\
13.04 & 12.66 & Father: White Collar Worker \\
17.07 & 18.53 & Father: Self Employed \\
9.53 & 8.92 & Father: Civil Servant \\
& & \\
87.38 & 88.06 & Mother: General School \\
9.79 & 8.87 & Mother: Intermediate School \\
2.82 & 3.06 & Mother: Grammar School \\
14.93 & 14.15 & Mother: Blue Collar Apprenticeship \\
1.13 & 1.39 & Mother: Vocational School after Secondary School \\
12.35 & 11.20 & Mother: White Collar Apprenticeship \\
1.13 & 1.39 & Mother: University or Polytechnics Education \\
\hline \hline
\end{tabular}


All information on the parents refers to characteristics when the individual was 15 years old. Besides educational characteristics, we also have information about the professional class of the father, and whether the respective parent participated in the labour force. The numbers reveal that, on average, educational attainments of both mother and father are lower than those of the offspring. In particular, there seems to be a remarkable increase in grammar school education. Also, the differences between males and females are much more pronounced in the parents' generation. While intermediate school certificates are about equally frequent for male and female parents, fathers hold a grammar school degree nearly three times as often, and an academic degree 5 times as often.

Based on the year of birth of the individuals in the sample we define 4 cohorts. The first cohort comprises individuals who were born between 1920 and 1937. We chose this date because these individuals decided about secondary school before or during the Second World War. Individuals in cohort 2 were born before 1946, and therefore entered secondary school during the first ten years after World War Two. Individuals in cohort 3 were born before 1956, and individuals in cohort 4 before 1966. Since our working sample is restricted to those individuals who were at least 21 in 1987, all individuals decided upon secondary schools no later than 1975. Table (2) shows the cohort definition and the number of cases in each cohort. The percentage of women in cohort 1 is slightly higher than the percentage of men, which is a result of the Second World War as well as the higher life expectancy of females.

\section{Empirical Analysis}

The empirical analysis consists of 5 parts: first, we illustrate the transitions from secondary school to post school education. Secondly, we analyse the association between 
Table 2: Definition of Cohort Dummies, Number of Cases

\begin{tabular}{l|l|cccc}
\hline \hline Variable & Description & \multicolumn{2}{|c}{ Males } & \multicolumn{2}{c}{$\underline{\text { Females }}$} \\
& & Cases & Mean & Cases & Mean \\
\hline Cohort 1 & Born between 1920 and 1936 & 886 & 25.30 & 886 & 28.34 \\
Cohort 2 & Born between 1937 and 1946 & 750 & 25.81 & 732 & 23.76 \\
Cohort 3 & Born between 1947 and 1956 & 624 & 21.48 & 690 & 22.40 \\
Cohort 4 & Born between 1957 and 1966 & 796 & 27.40 & 785 & 25.48 \\
\hline \hline
\end{tabular}

parents' characteristics, and secondary school track of the individual. Third, we illustrate changes over time, and point out differences between males and females. Fourth, we investigate the association between educational achievements and wages. Fifth, we illustrate the impact of parental background on the earnings of the individual via its influence on the secondary school track. We estimate models where we allow parental characteristics to affect the child's wages by shifting probabilities of secondary school attainments.

Our analysis is purely descriptive. We do not intend to interpret any parameters as structural, and variations in parental background are not assumed exogenous to any of the estimated outcome equations. For instance, we do not attempt to answer the question whether the higher probability of grammar school attendance of children born to academic parents is due to these children having higher learning abilities, or due to academically educated parents tending to choose higher track seondary schools for the child. To disentangle these effects creates serious identification problems, which we feel we can not satisfactorily address with our data. The coefficients we estimate are a combination of the two effects. 


\subsection{Secondary School Choice and Post School Education}

We argue above that the choice of the secondary school track is strongly associated with later educational choices. In tables (6) and (7) in the appendix, we show cross tabulations for secondary school degrees and subsequent educational choices for females and males, respectively. The numbers refer to the first three cohorts only, since individuals in the fourth cohort may still be in education, predominantly at universities. The three panels distinguish between the three secondary schools: general, intermediate, and grammar. The variable "other" summarises individuals with post secondary education not included in any of the other categories.

Table 3: Correlation Secondary School - Post-Secondary Education

\begin{tabular}{|c|c|c|c|c|c|c|c|c|c|c|c|c|}
\hline \multirow[t]{2}{*}{$\begin{array}{l}\text { Secondary } \\
\text { Education }\end{array}$} & \multicolumn{2}{|c|}{$\begin{array}{l}\text { No further } \\
\text { Education }\end{array}$} & \multicolumn{2}{|c|}{$\begin{array}{c}\text { Blue Collar } \\
\text { Apprenticeship }\end{array}$} & \multicolumn{2}{|c|}{ Voc. School } & \multicolumn{2}{|c|}{$\begin{array}{l}\text { White Collar } \\
\text { Apprenticeship }\end{array}$} & \multicolumn{2}{|c|}{$\begin{array}{l}\text { University } \\
\text { Degree }\end{array}$} & \multicolumn{2}{|c|}{ Other } \\
\hline & Corr. & StdE. & Corr. & StdE. & Corr. & StdE. & Corr. & StdE. & Corr. & StdE. & Corr. & StdE. \\
\hline & Male & & & & & & & & & & & \\
\hline General & 0.68 & 0.059 & 0.76 & 0.025 & -0.30 & 0.052 & -0.01 & 0.066 & -0.97 & 0.007 & -0.05 & 0.137 \\
\hline Intermediate & -0.68 & 0.092 & -0.43 & 0.055 & 0.66 & 0.036 & 0.29 & 0.069 & -0.42 & 0.086 & 0.19 & 0.154 \\
\hline \multirow[t]{2}{*}{ Grammar } & -0.69 & 0.086 & -0.92 & 0.020 & -0.48 & 0.075 & -0.31 & 0.089 & 0.98 & 0.003 & -0.09 & 0.182 \\
\hline & \multicolumn{12}{|c|}{ Females } \\
\hline General & 0.67 & 0.032 & 0.51 & 0.071 & -0.10 & 0.048 & -0.53 & 0.047 & -0.99 & 0.007 & -0.41 & 0.105 \\
\hline Intermediate & -0.59 & 0.043 & -0.39 & 0.089 & 0.39 & 0.045 & 0.53 & 0.048 & -0.43 & 0.119 & 0.49 & 0.098 \\
\hline Grammar & -0.80 & 0.050 & -0.67 & 0.124 & -0.68 & 0.070 & 0.22 & 0.096 & 0.99 & 0.002 & -0.05 & 0.235 \\
\hline
\end{tabular}

Goodman-Kruskal Correlation Coefficients (Standard Errors), computed as $\gamma=\frac{P-Q}{P+Q}$, where $P$ is the number of concordant, and $Q$ the number of discordant pairs of observations.

Table (3) displays Goodman - Kruskal correlation coefficients, which summarise the cross tabulations. This coefficient can be interpreted as the difference in probability of like rather than unlike responses for the two education measures when two individuals are chosen at random. We have printed significant positive correlations in bold. 
The numbers reflect the same pattern as the percentages in tables (6) and (7) in the appendix.

The entries in the upper panel of table (3) refer to males. They illustrate that secondary school attendance for males is strongly associated with post-secondary education. Having attended a secondary general school is strongly and significantly correlated with a subsequent apprenticeship in the vocational sector, and more so with training in blue-collar apprenticeship jobs. Intermediate school graduates tend to obtain further education by attending vocational schools, or joining white collar apprenticeship schemes, while being a grammar school graduate is strongly correlated with attending university. While the low occurrence of upward transitions (from general school to university) is not so surprising, the numbers also suggest that downward transitions are not frequent. The numbers in the last block indicate that the association between grammar school degree, and a blue collar apprenticeship is very low.

The numbers for females (lower panel) are similar. While males with general secondary school degrees tend to enrol in blue-collar apprenticeships, and males with intermediate school degrees in white collar apprenticeships or vocational schools, females from both intermediate and grammar schools tend to enrol in white rather than blue collar apprenticeships.

The numbers in tables (6) and (7) in the appendix show that the ratio of females with a general school education and without further vocational training dropped dramatically over cohorts. On the other side, the share of former general school pupils in vocational schools nearly doubles from cohort 1 to cohort 2 . The fraction of females and males with a general secondary school degree who decide on no further education dropped also systematically over cohorts.

For both males and females with general secondary school degrees the percentage 
of blue-collar apprenticeships is quite stable over time. More males enrol in blue collar apprenticeships than in white collar apprenticeships, while the opposite is the case for females. It is interesting that quite a high fraction of both males and females with a grammar school certificate demand white-collar vocational training, although the percentage is slightly decreasing over time, and for both sexes. By far the highest fraction of grammar school graduates, however, decides on an academic education. Here the percentage of females is steadily increasing, and approaches the level of males.

The picture that emerges from these numbers is that for males there is a strong association between general school degrees and blue-collar vocational training, intermediate school degrees and white-collar or vocational school training, and grammar school and academic degrees. For females, both general and intermediate school graduates tend to vocational schools and to white, rather than blue collar apprenticeships. These strong associations emphasise the importance of secondary school choices for understanding subsequent choices within the German educational system.

\subsection{Factors associated with Secondary School Choice}

We now have a closer look at the association between parental characteristics, and the children's secondary school track. We model the allocation to secondary school tracks as an ordered probit model, where we distinguish between the three categories of general, intermediate, and grammar school. To interpret the estimation results, we calculate the differential marginal effects of explanatory variables on the probability that an individual attends grammar or intermediate school, as compared to general school.

We first estimate models for males and females separately where we pool all cohorts.

We allow for cohort effects in a flexible way by introducing a polynomial of the year of 
birth of degree $4 .{ }^{4}$ Secondary school choice is explained by variables that reflect parents' school and post-school education, and variables about the father's professional class.

Table (4) presents the differential marginal effects of variables on the probability of graduating from intermediate and grammar school, as opposed to a general school. We report standard errors of these probabilities in parenthesis. ${ }^{5}$ All effects are calculated for the average sample individual in the respective subgroup.

Reference group are parents where father and mother have a general secondary school education, no after-secondary school education, and where the father has a blue-collar job. There are several noteworthy results in table (4). While for males, an intermediate or grammar school degree held by the father increases the probability that the individual attends grammar school by more than the probability that the individual attends intermediate school (relative to general school), the opposite is the case for females. This indicates that intermediate school attendance is considered to be a sufficient education for female offsprings, while better educated fathers tend to send their sons to a grammar school rather than an intermediate school.

The variables that characterise the post school education of the father are all significant and positive. Again, while any after school degree of the father increases the probabilities of the son's grammar school attendance more than the probability of son's intermediate school attendance, the opposite is the case for daughters. White collar apprenticeship, or vocational after school education of the father affects higher school track attendance of the individual more strongly than blue collar after school education.

\footnotetext{
${ }^{4}$ The null hypothesis for equal parameters for both genders is rejected at the 5 percent level, using a likelihood-ratio test. We therefore base our further analysis on gender specific estimations.

${ }^{5}$ We compute the standard errors by simulation. We draw 500 observations of the estimated parameters from their asymptotic normal distribution, and compute the standard errors of the predicted differential marginal probabilities.
} 
Table 4: Marginal Differential Effects of Parents' Characteristics

\begin{tabular}{l|cccc|cccc}
\hline \hline & \multicolumn{4}{|c}{ Males } & \multicolumn{5}{c}{ Females } \\
\hline & \multicolumn{2}{|c}{ Intermediate vs. } & \multicolumn{2}{c}{ Grammar vs. } & \multicolumn{2}{c}{ Intermediate vs. } & \multicolumn{2}{c}{ Grammar vs. } \\
& General & \multicolumn{2}{c}{ General } & General \\
\hline Variable & Coeff. & StdE. & Coeff. & StdE. & Coeff. & StdE. & Coeff. & StdE. \\
\hline Father Grammar School & 0.275 & 0.072 & 0.343 & 0.090 & 0.359 & 0.074 & 0.297 & 0.061 \\
Father Intermed School & 0.286 & 0.045 & 0.357 & 0.055 & 0.273 & 0.054 & 0.226 & 0.044 \\
Mother Grammar School & 0.360 & 0.106 & 0.450 & 0.133 & 0.282 & 0.115 & 0.234 & 0.095 \\
Mother Intermed School & 0.260 & 0.053 & 0.325 & 0.068 & 0.204 & 0.058 & 0.169 & 0.048 \\
Father Academic Ed & 0.546 & 0.084 & 0.682 & 0.104 & 0.471 & 0.086 & 0.390 & 0.071 \\
Father Blue C. Appr. & 0.175 & 0.038 & 0.219 & 0.047 & 0.147 & 0.042 & 0.121 & 0.034 \\
Father White C. Appr. & 0.302 & 0.056 & 0.377 & 0.069 & 0.342 & 0.060 & 0.283 & 0.049 \\
Father Vocational Sch. & 0.229 & 0.055 & 0.286 & 0.068 & 0.308 & 0.062 & 0.254 & 0.051 \\
Mother Academic Ed & 0.041 & 0.131 & 0.051 & 0.164 & 0.376 & 0.139 & 0.311 & 0.114 \\
Mother Blue C. Appr. & 0.072 & 0.038 & 0.090 & 0.047 & 0.022 & 0.043 & 0.018 & 0.036 \\
Mother White C. Appr. & 0.120 & 0.039 & 0.150 & 0.048 & 0.198 & 0.045 & 0.164 & 0.037 \\
Mother Vocational Sch. & -0.002 & 0.113 & -0.003 & 0.141 & 0.207 & 0.123 & 0.171 & 0.102 \\
Father White Collar Job & 0.198 & 0.045 & 0.247 & 0.056 & 0.309 & 0.050 & 0.255 & 0.041 \\
Father Self Employed & 0.182 & 0.039 & 0.227 & 0.049 & 0.259 & 0.041 & 0.214 & 0.033 \\
Father Civil Servant & 0.301 & 0.054 & 0.375 & 0.067 & 0.322 & 0.060 & 0.266 & 0.050 \\
Year Born $/ 10$ & -2.769 & 2.107 & -3.456 & 2.625 & -4.652 & 2.235 & -3.849 & 1.840 \\
Year Born ${ }^{2} / 10^{3}$ & 10.191 & 7.822 & 12.719 & 9.747 & 19.861 & 8.490 & 16.431 & 6.991 \\
Year Born ${ }^{3} / 10^{5}$ & -15.015 & 12.453 & -18.743 & 15.520 & -33.587 & 13.794 & -27.787 & 11.355 \\
Year Born ${ }^{4} / 10^{7}$ & 7.739 & 7.194 & 9.662 & 8.967 & 19.957 & 8.113 & 16.510 & 6.678 \\
\hline \hline
\end{tabular}

Ordered probit models. Marginal Differential Effects and their standard errors are reported. 
As one should expect, the association between the child's higher secondary school track education and academic education of the father is strong. The same patterns prevails for mother's after school education.

All job characteristics of the father are strongly significant predictors for child's (relative) secondary school choice. Notice that coefficient estimates of father's professional characteristics are conditional on father's educational achievement and, therefore, reflect the pure association between job characteristics, and school choice. Accordingly, the working environment and the associated social relations and peer group of the father seem to play an important role for the secondary school education of the child.

These estimates suggest that the association between parental educational attainment and profession and the secondary track education the child follows is substantial. The estimates show some interesting differences between males and females: characteristics of parents which are strongly associated with a grammar school education for males, are strongly associated with intermediate school education for females. This is in line with the relative overall tendency of females to enrol in intermediate schools, as depicted in figure 2 .

\subsection{Changes in Secondary School Education}

The estimates in the last section indicate that the probability of attending a grammar school is strongly associated with the educational background of the parents. In addition, there are changes over time, which we try to capture with a cohort polynomial. ${ }^{6}$

To illustrate how the probabilities for the various school levels change over time, we simulate intermediate and grammar school attendance probabilities for parents

\footnotetext{
${ }^{6}$ For both males and females, the polynomial terms are jointly significant at the 1 percent level.
} 
with different educational background, and different professional class. Probabilities for individuals who come from a family with typical working class background are displayed in figure (3), where parental working class background is defined as a father with general secondary school education, blue collar apprenticeship and blue collar job, and a mother with general secondary school education.

In figure (4), we show an individual whose father has a grammar school degree, an academic degree, and a white collar job, and whose mother has a grammar school degree and an academic education. Calculation of the probabilities is done for all groups born between 1921 and 1966. The figures illustrate the evolution of probabilities of intermediate and grammar school attendance over time. Solid lines represent males, and dashed lines represent females. The lines for the various school types carry different symbols, which are explained in the figures.

Figure 3: School Attendance Probabilities, Working Class Parents

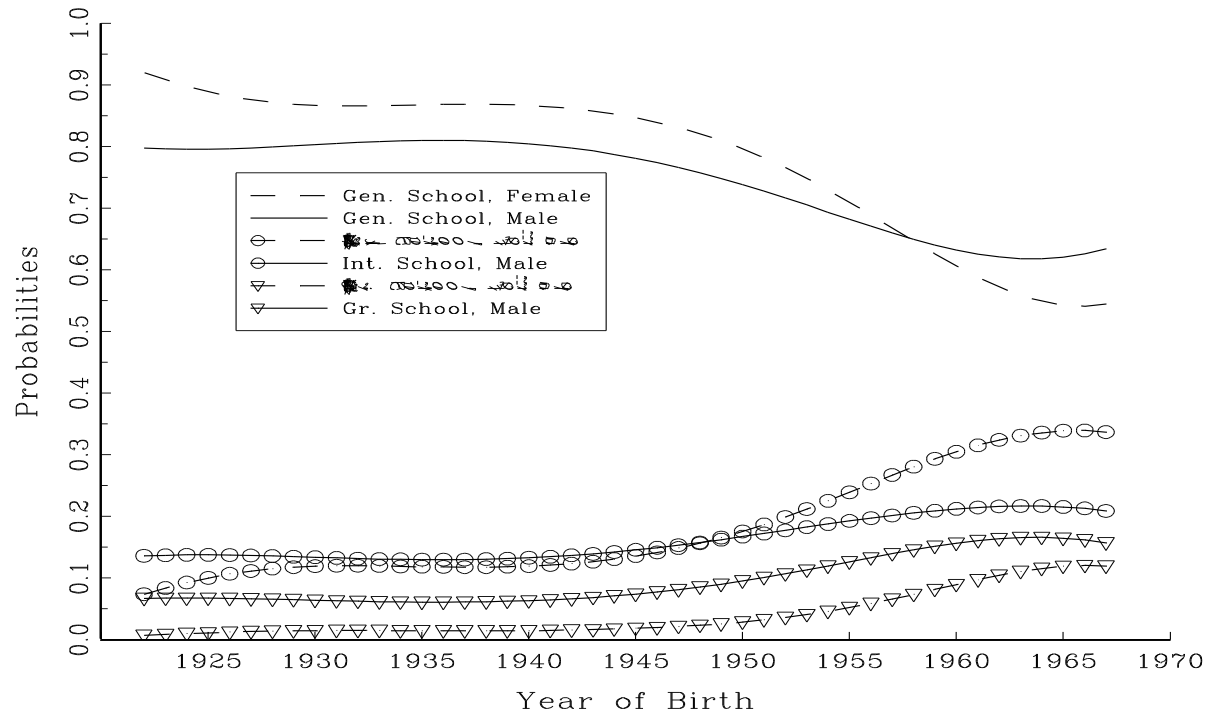

The figures show the dramatic differences in probabilities of grammar school attendance for individuals with different parental background. While the probability of 
Figure 4: School Attendance Probabilities, Academic Parents

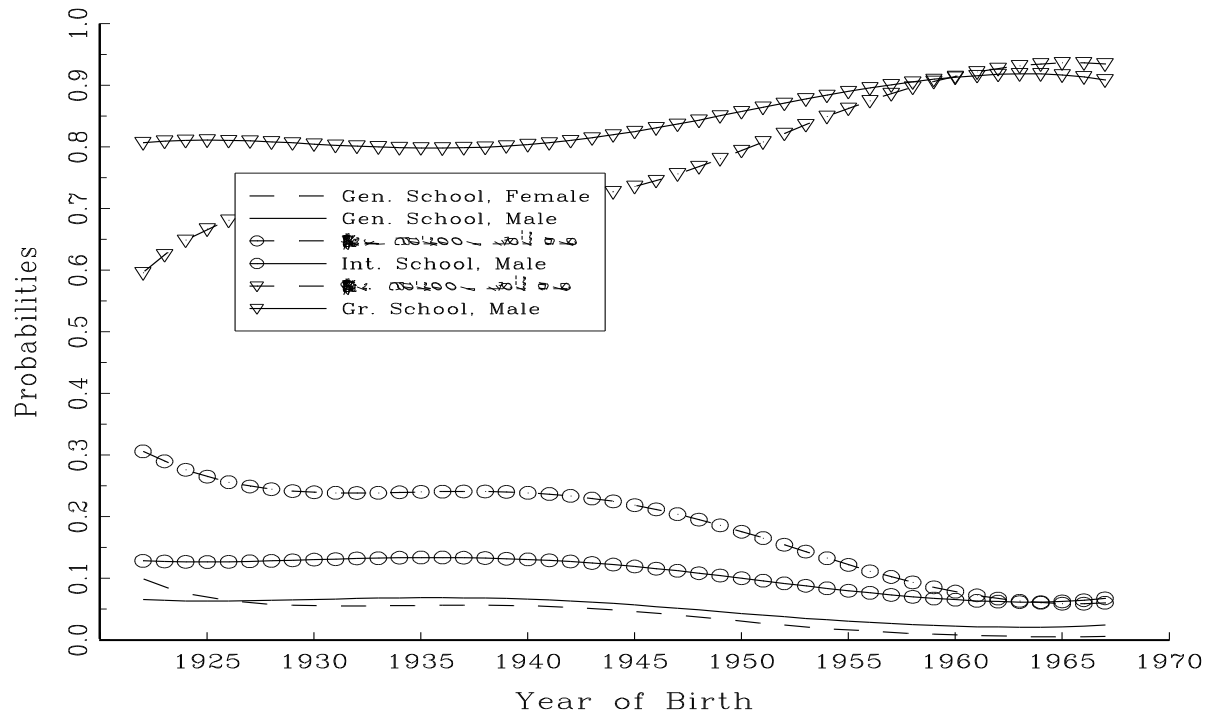

grammar school attendance is always below 20 percent for a male working class individual, it is always above 70 percent for an individual with academic family background.

There is a tendency towards convergence over time. For individuals with working class background, a decline in the share of general school education is visible, accompanied by an increase in intermediate and grammar schools. The convergence is more pronounced for females than for males. While in early cohorts the percentages of both intermediate and grammar school attendance is higher for males, females overtake males with respect to intermediate degrees in later cohorts, and the gap for grammar school attendance is closed at the end of the observation period.

For individuals with academic background, the probability of the child attending grammar school is about 40 percent for females (which is equal to the probability of attending intermediate schools), and 80 percent for males born in 1921. For males, this probability is relatively stable over time, with only a slight increase in the second half of the century. For females, there is a strong increase, and for those born in 1966, 
probabilities of grammar school attendance are nearly equal to those for males. On the other hand, the probability of general school education is never higher than 10 percent, and it approaches zero for both genders in the last cohort. The increase in grammar school attendance for females is compensated for by a decrease in intermediate school attendance. In contrast, for females with working class background, there seems to be a shift from general schools to intermediate schools, but not grammar schools.

These figures suggest low educational mobility, with a slight tendency towards convergence. Furthermore, they illustrate a significant shift towards better education for females from different parental background, and a closing gap for individuals of the two genders born into different parental backgrounds during the second half of the last century.

\subsection{Educational Achievements and Wages}

In the last section, we have illustrated that parental background is strongly related to educational achievements of the child. In this section, we investigate how parental background is associated with wages, via its impact on the education of the child. We first discuss results of regressing wages on educational achievements, and parental background. We then estimate wage equations jointly with the secondary school choice equation, and simulate wage patterns for individuals from different parental backgrounds.

Age at one point in time is related to wages in two ways: First, by positioning the individual on his/her life cycle career path. Secondly, by defining the time of labour

market entry, which may have lasting effects on the individual's career path due to favourable or unfavourable labour market conditions at labour force entry. This effect is usually referred to as cohort effect. A further, indirect impact of age works via ed- 
ucational achievements, by affecting the track of secondary school education, keeping parental background constant. This is the cohort effect on education we have discussed above. In this section, we isolate the first two effects, and discuss the estimated relationship between individual's educational background and wages. In the next section, we isolate the last effect, which affects wages via the educational track the individual has followed, and illustrate changes over time by comparing an individual of working class background, and of academic background.

To identify the wage-age patterns of individuals, we need to separate out age effects from cohort and time effects. Panel data allows us to identify only two of the three effects. Our strategy is to eliminate time effects first by making use of another longitudinal data source. This data set is a social security based data source, which constitutes a 1 percent sample of the entire German labour force. It is drawn from an administrative data base (see Dustmann and Meghir 2001 for details on this data). From this source, we construct a sample of young workers, whose first spell in the labour market we observe for the years 1984-1990. Variation in entry wages of these workers are due to variation in educational background and entry year only, since their labour market experience is equal to zero. We use the estimated time effects from wage regressions of this sample to de-trend wages for the first 7 years of the panel (between 1984 and 1990). We then estimate wage regressions, conditioning on educational achievements, an age polynomial, and cohort dummies, which are defined according to the classification in table (1).

The wage equations we estimate are given by

$$
\ln w_{i t}^{g}=\alpha_{0}^{g}+\alpha_{1}^{g} i s c h_{i}+\alpha_{2}^{g} g s c h_{i}+\alpha_{3}^{g} \operatorname{coh}_{i}+P_{i}(\text { age }) \beta^{g}+T R_{i}^{\prime} \gamma^{g}+u_{i t}
$$

where $i s c h$ and $g s c h$ are dummy variables for intermediate and grammar school at- 
tendance, coh are cohort dummies, $T R$ is a vector of further educational achievements, and $P(a g e)$ is a polynomial in age of degree 3. The indices $i, t, g$ stand for individuals, time, and gender. We do not intend to interpret the coefficients in a structural way; thus, we define the coefficients to be such that $\mathrm{E}\left(u_{i t} \mid\right.$ isch, gsch, coh, $P($ age $\left.), T R\right)=0$.

In columns 1 and 3 of table (5), we display estimates where we condition on secondary school education, as well as after-secondary school attainments. Omitted category is individuals with a general school degree, and no further training. According to these estimates, an intermediate school degree is associated with an increase in log wages of 0.15 and 0.23 for males and females, respectively. A grammar school degree is associated with an increase in log wages by about 0.25 (males) and 0.32 (females). The larger coefficient for females may be due to selection.

Blue collar and white collar apprenticeships, as well as vocational school attendance lead to further increases in the expected wage, with white collar apprenticeships having the largest coefficients for both genders. University education adds substantially to after-secondary school wages for both genders.

The cohort dummies are significant for males, indicating that (compared to the first cohort) wages in cohorts 2 and 3 are slightly higher. Wages in cohort 4 are lower again, which may be due to the fact that many university graduates in this cohort have not entered the labour market yet. For females, cohort effects are mostly insignificant.

In columns 2 and 4, we present results where we regress on secondary school degrees only. The coefficients can be interpreted as the association between the respective secondary school degree and wages for an individual with average further attainments following the two degrees. It is a reduced form specification, compared to regressions in columns 1 and $3 .^{7}$ General school attainment (and expected further training achieve-

\footnotetext{
${ }^{7}$ To see this, consider the above wage regression. The coefficients on the secondary education
} 
Table 5: Wage Regressions

\begin{tabular}{|c|c|c|c|c|c|c|c|c|}
\hline & \multicolumn{4}{|c|}{ Males } & \multicolumn{4}{|c|}{ Females } \\
\hline & \multicolumn{2}{|c|}{1} & \multicolumn{2}{|c|}{2} & \multicolumn{2}{|c|}{3} & \multicolumn{2}{|c|}{4} \\
\hline Variable & Coeff. & StdE. & Coeff. & StdE. & Coeff. & StdE. & Coeff. & StdE. \\
\hline Constant & 1.611 & 0.155 & 1.246 & 0.160 & 2.196 & 0.239 & 1.324 & 0.246 \\
\hline Intermediate School & 0.148 & 0.007 & 0.196 & 0.006 & 0.236 & 0.010 & 0.289 & 0.010 \\
\hline Grammar School & 0.257 & 0.010 & 0.433 & 0.006 & 0.317 & 0.016 & 0.546 & 0.012 \\
\hline Blue Collar Apprenticeship & 0.105 & 0.008 & - & - & 0.026 & 0.015 & - & - \\
\hline White Collar Apprenticeship & 0.180 & 0.010 & - & - & 0.165 & 0.010 & - & - \\
\hline Vocational Training & 0.142 & 0.009 & - & - & 0.159 & 0.013 & - & - \\
\hline University Education & 0.378 & 0.013 & - & - & 0.499 & 0.021 & - & - \\
\hline age/10 & 0.493 & 0.133 & 0.857 & 0.137 & -0.182 & 0.207 & 0.574 & 0.213 \\
\hline $\operatorname{age}^{2} / 10^{3}$ & -0.606 & 0.353 & -1.470 & 0.364 & 1.158 & 0.561 & -0.661 & 0.579 \\
\hline $\operatorname{age}^{3} / 10^{5}$ & 0.140 & 0.295 & 0.795 & 0.304 & -1.391 & 0.477 & -0.023 & 0.494 \\
\hline cohort 2 & 0.054 & 0.015 & 0.054 & 0.015 & -0.065 & 0.026 & -0.073 & 0.027 \\
\hline cohort 3 & 0.070 & 0.024 & 0.063 & 0.024 & -0.019 & 0.040 & -0.035 & 0.041 \\
\hline cohort 4 & 0.036 & 0.029 & 0.015 & 0.030 & 0.007 & 0.048 & -0.012 & 0.050 \\
\hline N. Obs. & \multicolumn{2}{|c|}{12598} & \multicolumn{2}{|c|}{12598} & \multicolumn{2}{|c|}{7738} & \multicolumn{2}{|c|}{7738} \\
\hline
\end{tabular}

ments associated with general school attainment) is the reference group. As expected, variables (unconditional on further training $T R$ ) are then given by (where we omit, for the sake of simplicity, cohort and age variables, and assume that $T R$ consists of only one variable):

$$
\mathrm{E}(\ln w \mid i s c h, g s c h)=\alpha_{0}+\alpha_{1} i s c h+\alpha_{2} g s c h+\gamma \mathrm{E}(T R \mid i s c h, g s c h) .
$$

Suppose that the conditional expectation $E(T R \mid h s c h, m s c h)$ is linear, and has the following form:

$$
E(T R \mid i s c h, g s c h)=\delta_{0}+\delta_{1} i s c h+\delta_{2} g s c h,
$$

which is the expected post school training received, conditional on secondary school education. Combining with (2) gives

$$
\begin{aligned}
\mathrm{E}(\ln w \mid i s c h, g s c h) & =\left(\alpha_{0}+\gamma \delta_{0}\right)+\left(\alpha_{1}+\gamma \delta_{1}\right) i s c h+\left(\alpha_{2}+\gamma \delta_{2}\right) g s c h \\
& =\tilde{\alpha}_{0}+\tilde{\alpha}_{1} i s c h+\tilde{\alpha}_{2} g s c h
\end{aligned}
$$


coefficients for the two school categories increase, and are slightly larger for females. Compared to a male individual with general schooling (and the associated average further training), a grammar school graduate (with average weighted further educational achievements) earns about $54\left(e^{0.433}-1\right)$ percent higher wages.

\subsection{Wages and Parental Background}

We have illustrated above that there is some convergence in educational track choice over cohorts between individuals with different parental background. We now simulate how this translates into log wages. We predict log wages, conditional on parental background only. In terms of equation (3), this corresponds to expected wages, conditional on a set of parental background information $P B$ :

$$
\begin{aligned}
\mathrm{E}(\ln w \mid P B) & =\tilde{\alpha}_{0}+\tilde{\alpha}_{1} \mathrm{E}(i s c h \mid P B)+\tilde{\alpha}_{2} \mathrm{E}(\text { gsch } \mid P B) \\
& =\tilde{\alpha}_{0}+\tilde{\alpha}_{1} \operatorname{Prob}(i s c h \mid P B)+\tilde{\alpha}_{2} \operatorname{Prob}(\text { gsch } \mid P B)
\end{aligned}
$$

Based on this specification, we predict log wages for an individual from a working class background, and for an individual from an academic background, where we use the same definitions as in the previous section. We want to isolate the (relative) indirect effect being born into different cohorts has on wages, via its effect on education only. We eliminate time and cohort effects in the wage equation by conditioning on cohort dummies and de-trending wages first, as explained above. We choose 1987 as a base

so that coefficients in the reduced specification represent the association between wages and, for instance, a grammar school degree, and the expected further educational achievements, conditional on having achieved a grammar school education. 
Figure 5: Wage Profiles, Males

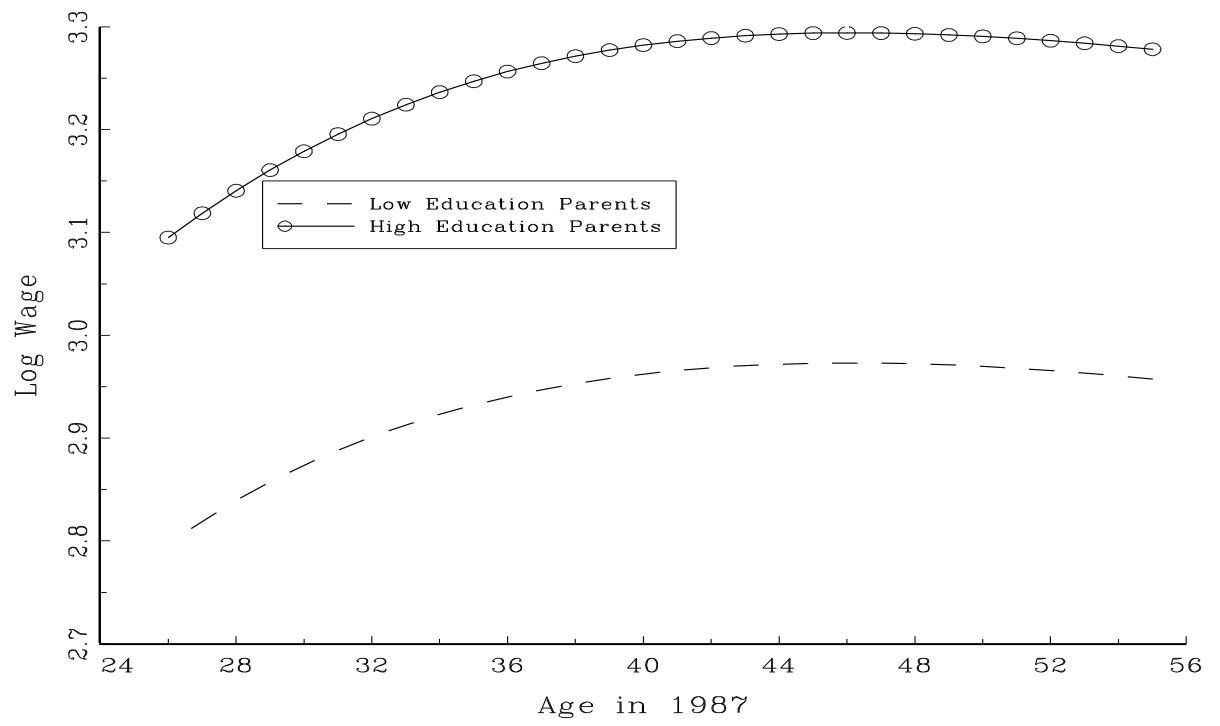

year. Individual's age affects wages then by positioning the individual on his/her life cycle earnings profile, and by its effect on the educational track followed, via the cohort into which an individual is born. We assume that the first (life-cycle earnings) effect is the same for individuals of different educational background, and we condition on it by adding a third order age polynomial to the wage equation. This allows us then to isolate any remaining relative changes between individuals of different educational background, which are due to the last effect only.

We obtain the probabilities $\operatorname{Prob}(i s c h \mid P B)$ and $\operatorname{Prob}(g s c h \mid P B)$ from our ordered probit model. We simulate (de-trended) wages along the age profile, after conditioning out direct cohort effects in the wage equation. Since we assume that direct wageage profiles are the same for individuals with different background, any changes in differences in wages between individuals with different parental background are due to indirect cohort effects, via educational achievements. In other words, the variation in wage differences for different cohorts is due to shifts across cohorts in the probabilities 
of obtaining higher secondary education, as illustrated in the previous section.

In figures (5) and (6), we plot the predicted wage profiles for males and females, respectively. In table (8) in the appendix, we report the wage differences (according to parental background) for the various age groups, and the t-ratios of the differences between wages at different ages for individuals from academic and working class background..$^{8}$

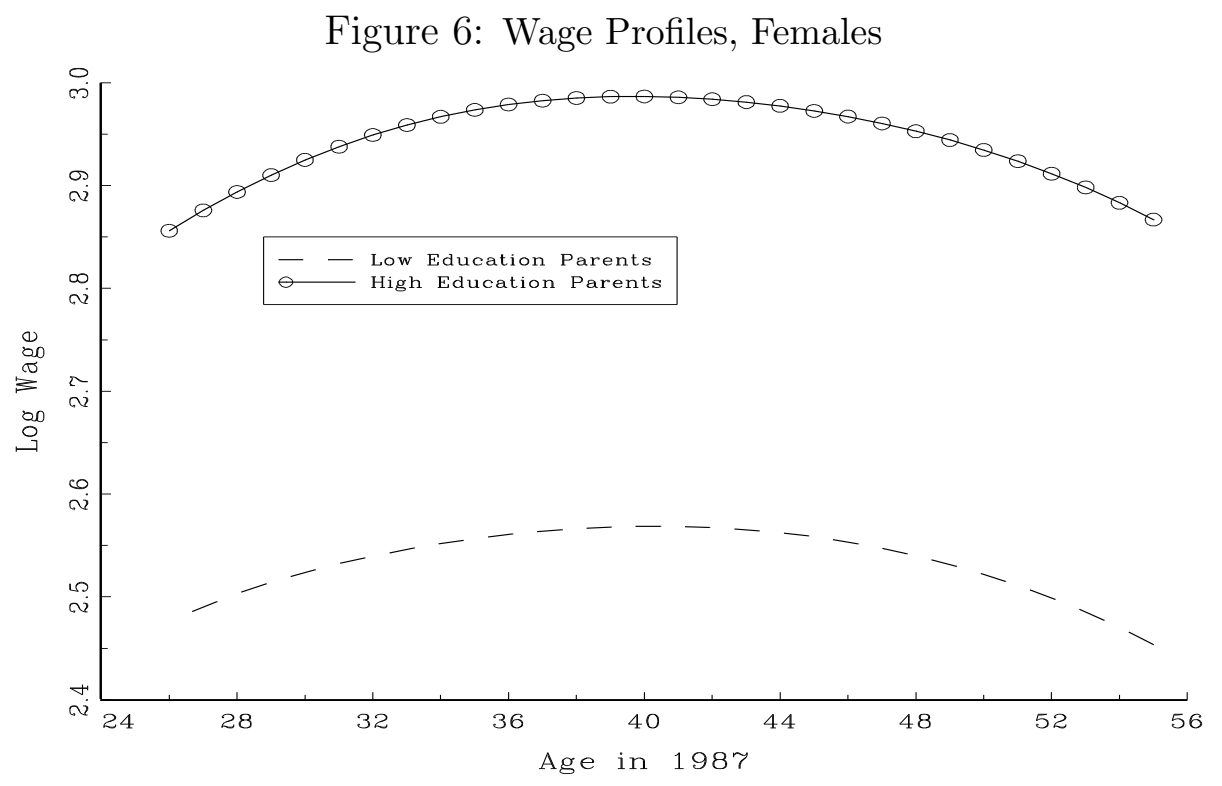

Wage differentials for individuals with different parental background are sizeable. For males who are 26 years old in 1987, the log wage differential between an individual born into an academic family and an individual born into a working class family is about 0.3 , translating into a 35 percent differential. For females, the differential is larger at 46 percent.

\footnotetext{
${ }^{8}$ To compute the standard errors, we take account of the fact that the parameters in the wage equation, as well as the parameters in the ordered probit model (used to form the predictions of secondary school attendance) are random variables. Computation of the standard errors is based on simulations.
} 
The figures indicate only a slight convergence in wage profiles of individuals in younger cohorts, relative to older cohorts. On average, male individuals from a working class background and born in 1961 obtain wages which are about 35 percent lower than those of individuals from an academic background; this difference increases by only 2.3 percent for individuals born in 1932. This increase is due to the larger relative disadvantage in acquiring higher track education for individuals from working class

background who were born in 1932, compared to those born in 1961. Thus, the slight convergence we observe in terms of secondary track education between individuals of different background translates in a small convergence in later earnings.

\section{Conclusion}

In this paper, we argue that an important factor for explaining the degree of intergenerational mobility of income status, and differences in this parameter across countries, is the influence parents may have on early school track decisions of the child. This, in turn, is related to institutional features of the education system, in particular the age at which the secondary school track choice has to be taken. In Germany, primary, secondary and post-school education is state provided, tuition-free, and there are no large differences in quality across schools of a given track. Despite that, we document a substantial immobility of educational achievement across generations. One reason for this may be the relatively young age at which the secondary track decision has to be taken, giving a high weight to parental advice. This particular feature of the German education system has been mostly overlooked, with scientists focussing on post secondary education, and first transitions into the labour market. Strong professional traditions in Germany may lead parents to consider the highest track schools not necessarily the best option for their child, and this may offset the effects of a tuition free 
education system.

Based on micro data, we analyse the association between parents' characteristics, and secondary school choice of the child. We estimate ordered probit models, where we use occupational and educational characteristics of the parents as predictors. We distinguish between four birth cohorts, and between males and females. We first predict secondary school graduation probabilities for both males and females where we distinguish parents with high educational and professional background, and parents with low educational and professional background. The difference between the child's education between groups is remarkable. Furthermore, the gap across males and females regarding grammar education vanishes over time and, in the case of well educated parents, females even overtake males.

We then look at wages, and study the impact of parental background on later wages of individuals via its influence on secondary track school choice. As an illustration, we compare individuals from an academic family background, and a working class background. We establish substantial average wage differences. The convergence in educational achievements over time translates into only a small convergence in wages for individuals of different background.

The paper documents and illustrates the importance early educational choices may have on the future career of the individual. It suggests that differences in intergenerational transmission of education and income status, which we observe across countries, may be partly related to differences in features of basic educational institutions. Too little research has been devoted to this important issue. To obtain a full picture of individual's career patterns, we need to understand what determines the early educational decisions, and what is the impact on later choices. 


\section{References}

- Ben-Porath, Y. (1967): "The Production of Human Capital and the Life Cycle of Earnings," Journal of Political Economy, 75, 352-365

- Buechel, F., Frick, J.R., Krause, P., and G. Wagner (2000), "The Impact of Poverty on Childrens' School Attendance - Evidence from West Germany", mimeo, University of Berlin.

- Bjoerklund, A. and M. Jaenti (1997), "Intergenerational Mobility in Sweden compared with the United States", American Economic Review 87, pp.1021-1028.

- Buechtemann, C.F.; Schupp, J. and Soloff, D. (1993): "Roads to work: school-to-work transition patterns in Germany and the United States", Industrial Relations Journal, Vol. 24, 2, pp. 97 - 111.

- Bundesministerium für Bildung und Wissenschaft (1994): Berufliche Bildung in Deutschland, Bonn.

- Couch, K. A. (1994): "High School Vocational Education, Apprenticeship, and Earnings: A Comparison of Germany and the United States", Vierteljahreshefte zur Wirtschaftsforschung, Heft 1, 1994, pp. 10 - 18.

- Couch, K.A. and T.A. Dunn (1997): "Intergenerational Correlations in Labour Market Status: A Comparisson of the United States and Germany", Journal of Human Resources 32, pp.210-232.

- Dearden, L., Machin, S., and H. Reed (1997): "Intergenerational Mobility in Britain", The Economic Journal 107, 47-64.

- Ermisch, J. and M. Francesconi (2001): "Family Matters: Impacts of Family Background on Educational Attainments", Economica 68, pp. 137-156. 
- Feinstein, L, Symons, J (1999): "Attainment in Secondary School" Oxford-EconomicPapers 51, pages 300-321..

- Robertson,D, Symons,J (1996): "Do Peer Groups Matter? Peer Group versus Schooling Effects on Academic Attainment" London School of Economics Centre for Economic Performance Discussion Paper No 311.

- Jenkins, S (1987): 'Snapshots versus Movies: 'Lifecycle Biases' and the Estimation of Intergenerational Earnings Inheritance" European-Economic-Review 31, pages 1149-58.

- Merz, M. and A. Schimmelpfennig (1999): "Career Choices of German High School Graduates: Evidence from the German Socio-Economic Panel", EUI working paper No. $99 / 11$.

- Pischke, J.S. (1999): "Does Shorter Schooling Hurt Student Performance and Earnings? Evidence from the German Short School Years", mimeo, MIT.

- Riphahn, R. (1999): "Residential Location and Youth Unemployment: The Economic Geography of School-to-Work- Transitions", mimeo, University of Munich.

- Statistisches Bundesamt (1994): Statistisches Jahrbuch für die Bundesrepublik Deutschland, Wiesbaden.

- Steedman, H. (1993): "The Economics of Youth Training in Germany", The Economic Journal, Vol. 103, pp. 1279 - 1291.

- Solon, G. (1992): "Intergenerational Income Mobility in the United States", American Economic Review 82, pp. 393-408.

- Wiegand, J. (1999), "Four Essays on Applied Welfare Measurement and Income Distribution Dynamics in Germany 1985-1995”, PhD-Thesis, University College London.

- Winkelmann, (1996): "Training, Earnings and Mobility in Germany", Konjunkturpolitik, $42,275-298$. 
- Winkelmann, R. (1996) "Employment Prospects and Skill Acquisition of Apprenticeship Trained Workers in Germany", Industrial and Labor Relations Review, 49(4), 658-672.

- Zimmerman, D. (1992): "Regression towards Mediocrity in Economic Stature", American Economic Review 82, 409-429. 


\section{Appendix: Tables}

\section{Table 6: Transitions Secondary-After Secondary Education, Males}

\begin{tabular}{l|cccccccc}
\hline \hline Secondary & & No After-Sec. & Blue & Vocational & White & & & \\
Education & Cohort & Education & Collar & School & Collar & University & Other & No. Obs. \\
\hline General & Cohort 1 & 18.04 & 53.92 & 12.94 & 11.37 & 1.18 & 2.55 & 510 \\
Secondary & Cohort 2 & 14.79 & 53.45 & 13.21 & 14.40 & 0.99 & 3.16 & 507 \\
School & Cohort 3 & 10.92 & 53.50 & 18.21 & 15.13 & 0.28 & 1.96 & 357 \\
& All & 14.99 & 53.64 & 14.41 & 13.46 & 0.87 & 2.62 & 1374 \\
& & & & & & & & \\
Intermediate & Cohort 1 & 5.45 & 17.27 & 43.64 & 20.00 & 7.27 & 6.36 & 110 \\
Secondary & Cohort 2 & 1.75 & 27.19 & 43.86 & 14.91 & 8.77 & 3.51 & 114 \\
School & Cohort 3 & 0.81 & 23.39 & 41.13 & 25.81 & 7.26 & 1.61 & 124 \\
& All & 2.59 & 22.70 & 42.82 & 20.40 & 7.76 & 3.74 & 348 \\
& & & & & & & & \\
Grammar & Cohort 1 & 0.00 & 4.35 & 15.65 & 9.57 & 66.96 & 3.48 & 115 \\
Secondary & Cohort 2 & 0.78 & 3.10 & 3.10 & 9.30 & 80.62 & 3.10 & 129 \\
School & Cohort 3 & 6.29 & 2.80 & 6.29 & 6.29 & 77.62 & 0.70 & 143 \\
& All & 2.58 & 3.36 & 8.01 & 8.27 & 75.45 & 2.33 & 387 \\
\hline \hline
\end{tabular}

The column entries refer to percentages of respective after-secondary school education for the different secondary attainments. We distinguish between no further education, blue collar apprenticeship, vocational school, white collar apprenticeship, and university. For each cohort the numbers in a row add up to 100. 


\section{Table 7: Transitions Secondary-After Secondary Education, Females}

\begin{tabular}{|c|c|c|c|c|c|c|c|c|}
\hline $\begin{array}{l}\text { Secondary } \\
\text { Education }\end{array}$ & Cohort & $\begin{array}{c}\text { No After-Sec. } \\
\text { Education }\end{array}$ & $\begin{array}{c}\text { Blue } \\
\text { Collar }\end{array}$ & $\begin{array}{c}\text { Vocational } \\
\text { School }\end{array}$ & $\begin{array}{l}\text { White } \\
\text { Collar }\end{array}$ & University & Other & No. Obs. \\
\hline General & Cohort 1 & 62.43 & 11.09 & 17.60 & 6.95 & 0.00 & 1.92 & 676 \\
\hline Secondary & Cohort 2 & 44.22 & 15.11 & 29.10 & 8.96 & 0.19 & 2.43 & 536 \\
\hline \multirow[t]{2}{*}{ School } & Cohort 3 & 29.76 & 15.95 & 45.48 & 6.90 & 0.24 & 1.67 & 420 \\
\hline & All & 48.04 & 13.66 & 28.55 & 7.60 & 0.12 & 2.02 & 1632 \\
\hline Intermediate & Cohort 1 & 28.37 & 9.22 & 36.17 & 17.73 & 3.55 & 4.96 & 141 \\
\hline Secondary & Cohort 2 & 10.14 & 2.03 & 54.73 & 24.32 & 2.70 & 6.08 & 148 \\
\hline \multirow[t]{2}{*}{ School } & Cohort 3 & 11.93 & 6.25 & 44.32 & 28.98 & 2.27 & 6.25 & 176 \\
\hline & All & 16.34 & 5.81 & 45.16 & 24.09 & 2.80 & 5.81 & 465 \\
\hline Grammar & Cohort 1 & 7.14 & 5.36 & 10.71 & 19.64 & 51.79 & 5.36 & 56 \\
\hline Secondary & Cohort 2 & 6.25 & 2.08 & 6.25 & 18.75 & 64.58 & 2.08 & 48 \\
\hline \multirow[t]{2}{*}{ School } & Cohort 3 & 7.45 & 1.06 & 7.45 & 13.83 & 69.15 & 1.06 & 94 \\
\hline & All & 7.07 & 2.53 & 8.08 & 16.67 & 63.13 & 2.53 & 198 \\
\hline
\end{tabular}

The column entries refer to percentages of respective after-secondary school education for the different secondary attainments. We distinguish between no further education, blue collar apprenticeship, vocational school, white collar apprenticeship, and university. For each cohort the numbers in a row add up to 100. 
Table 8: Wage Differentials High/Low Educational Background

\begin{tabular}{l|cccc}
\hline \hline & \multicolumn{3}{|c}{ Males } & \multicolumn{2}{c}{ Females } \\
\hline Age & $\Delta \operatorname{lnw}$ & t-ratio & $\Delta \operatorname{lnw}$ & t-ratio \\
\hline 26 & 0.297 & 17.63 & 0.379 & 13.80 \\
27 & 0.299 & 19.32 & 0.385 & 15.20 \\
28 & 0.301 & 21.19 & 0.390 & 16.75 \\
29 & 0.302 & 23.27 & 0.395 & 18.49 \\
30 & 0.305 & 25.60 & 0.400 & 20.43 \\
31 & 0.307 & 28.17 & 0.405 & 22.59 \\
32 & 0.309 & 30.91 & 0.409 & 24.92 \\
33 & 0.311 & 33.58 & 0.412 & 27.24 \\
34 & 0.313 & 35.77 & 0.414 & 29.21 \\
35 & 0.314 & 36.93 & 0.416 & 30.30 \\
36 & 0.316 & 36.61 & 0.418 & 30.11 \\
37 & 0.317 & 34.86 & 0.418 & 28.60 \\
38 & 0.318 & 32.15 & 0.418 & 26.25 \\
39 & 0.319 & 29.10 & 0.418 & 23.58 \\
40 & 0.319 & 26.11 & 0.418 & 21.02 \\
41 & 0.320 & 23.42 & 0.417 & 18.73 \\
42 & 0.320 & 21.08 & 0.416 & 16.76 \\
43 & 0.320 & 19.08 & 0.415 & 15.10 \\
44 & 0.320 & 17.40 & 0.414 & 13.72 \\
45 & 0.320 & 15.97 & 0.414 & 12.56 \\
46 & 0.320 & 14.77 & 0.413 & 11.58 \\
47 & 0.320 & 13.75 & 0.413 & 10.76 \\
48 & 0.320 & 12.88 & 0.412 & 10.06 \\
49 & 0.320 & 12.14 & 0.412 & 9.465 \\
50 & 0.320 & 11.50 & 0.412 & 8.946 \\
51 & 0.320 & 10.95 & 0.412 & 8.490 \\
52 & 0.320 & 10.48 & 0.412 & 8.084 \\
53 & 0.320 & 10.06 & 0.412 & 7.715 \\
54 & 0.320 & 9.699 & 0.413 & 7.372 \\
55 & 0.320 & 9.369 & 0.413 & 7.046 \\
\hline \hline & & & &
\end{tabular}




\section{IZA Discussion Papers}

$\begin{array}{ll}\text { No. } & \text { Author(s) } \\ & \\ 355 & \text { J. Kluve } \\ & \text { H. Lehmann } \\ & \text { C. M. Schmidt }\end{array}$

356

C. Heady

T. Mitrakos

P. Tsakloglou

357

C. Knoppik

T. Beissinger

358

T. Beissinger

O. Buesse

359

M. Pflüger

360

J. Hansen

M. Lofstrom

361

M. C. Berger

J. S. Earle

K. Z. Sabirianova

362
J. Angrist

V. Lavy

363

H. Antecol

D. A. Cobb-Clark

S. J. Trejo

364

365

M. Jäntti

S. P. Jenkins

H. S. Nielsen

M. Rosholm

N. Smith

L. Husted

M. C. Regets
Title

Area

Date

Disentangling Treatment Effects of Polish Active

$4 / 6$

09/01

Labor Market Policies: Evidence from Matched

Samples

The Distributional Impact of Social Transfers in the European Union: Evidence from the ECHP

3

09/01

How Rigid are Nominal Wages?

09/01

Evidence and Implications for Germany

Bismarck versus Beveridge: Which Unemployment Compensation System is More Prone to Labor Market Shocks?

A Simple, Analytically Solvable Chamberlinian Agglomeration Model

2

The Dynamics of Immigrant Welfare and Labor Market Behavior

Worker Training in a Restructuring Economy:

4

09/01 Evidence from the Russian Transition

6

09/01

New Evidence on Classroom Computers and Pupil Learning

Immigration Policy and the Skills of Immigrants

2

to Australia, Canada, and the United States

Examining the Impact of Macro-Economic 3 Conditions on Income Inequality

Qualifications, Discrimination, or Assimilation? $\quad 1$ An Extended Framework for Analysing Immigrant Wage Gaps

Research and Policy Issues in High-Skilled International Migration: A Perspective with Data from the United States

Parental Background, Primary to Secondary

School Transitions, and Wages 